Research, Society and Development, v. 9, n. 11, e45291110274, 2020

(CC BY 4.0) | ISSN 2525-3409 | DOI: http://dx.doi.org/10.33448/rsd-v9i11.10274

\title{
A dialética da segurança pública e os desafios ao combate à criminalidade transnacional no âmbito das guerras irregulares
}

The dialectics of public security and the challenges to combat transnational crime in the framework of irregular wars

La dialética de la seguridad pública y los retos para combatir la delincuencia transnacional en el marco de guerras irregulares

Recebido: 15/11/2020 | Revisado: 17/11/2020 | Aceito: 18/11/2020 | Publicado: 21/11/2020

Rivaldo Ribeiro Sobral Neto

ORCID: https://orcid.org/0000-0002-2680-2322

Universidade Salvador, Brasil

E-mail: rivasobral@gmail.com

Murilo Jacques Barbosa

ORCID: https://orcid.org/0000-0001-7627-2684

Universidade Salvador, Brasil

E-mail:murilojb@gmail.com

\section{Resumo}

O estudo a seguir tem como objetivo avaliar a perspectiva do crime transnacional como um desafio para a segurança pública em um contexto de novas táticas de combate utilizadas pelas organizações criminosas. O papel das Forças Armadas e sua utilização para tal empreitada é questionado por extrapolar o real atributo do Exército nacional como garantidor do respeito ao sistema internacional com base na soberania westfaliana. Os planos estratégicos adotados pelo Estado brasileiro em particular, não vêm surtindo efeito, principalmente ao combate ao tráfico de drogas, no qual o Brasil se estabelece como segundo maior consumidor de cocaína. O fator da extensão territorial, amplas fronteiras e muitos pontos de saída pelo oceano Atlântico são fatores que prejudicam a eficácia ao combate de tal atividade. A metodologia adotada é a empírica-analítica, através de métodos qualitativos, com o fim de demonstrar os novos desafios contemporâneos por conta dos novos paradigmas de ação criminal no Brasil e no mundo. Chega-se à conclusão que o problema remete a uma questão socioeconômica mundial, e que a tratativa deste combate terá êxito caso ainda se insista em tratar os efeitos ao invés das causas. Palavras-chave: Segurança; Soberania; Criminalidade; Tráfico de drogas; Guerras irregulares. 


\section{Abstract}

The following study aims to assess the perspective of transnational crime as a challenge to public security in the context of new combat tactics used by criminal organizations. The role of the Armed Forces and their use for such an undertaking is questioned for extrapolating the real attribute of the national Army as a guarantor of respect for the international system based on Westphalian sovereignty. The strategic plans adopted by the Brazilian State in particular have not been having an effect, mainly in the fight against drug trafficking, in which Brazil establishes itself as the second largest consumer of cocaine. The factor of territorial extension, wide borders and many points of departure for the Atlantic Ocean are factors that hinder the effectiveness in combating such activity. The adopted methodology is the empirical-analytical one, through qualitative methods, in order to demonstrate the new contemporary challenges due to the new paradigms of criminal action in Brazil and in the world. The conclusion is reached that the problem refers to a global socioeconomic issue, and that the treatment of this fight will be successful if it still insists on treating the effects instead of the causes.

Keywords: Safety; Sovereignty; Crime; Drug trafficking; Irregular wars.

\section{Resumen}

El siguiente estudio tiene como objetivo evaluar la perspectiva del crimen transnacional como un desafío a la seguridad pública en el contexto de las nuevas tácticas de combate utilizadas por las organizaciones criminales. Se cuestiona el papel de las Fuerzas Armadas y su uso para tal emprendimiento por extrapolar el atributo real del Ejército nacional como garante del respeto al sistema internacional basado en la soberanía westfaliana. Los planes estratégicos adoptados por el Estado brasileño en particular no han tenido efecto, principalmente en la lucha contra el narcotráfico, en la que Brasil se consolida como el segundo mayor consumidor de cocaína. El factor de extensión territorial, amplias fronteras y muchos puntos de partida hacia el Atlántico son factores que dificultan la efectividad en el combate de dicha actividad. La metodología adoptada es la empírico-analítica, a través de métodos cualitativos, a fin de demostrar los nuevos desafíos contemporáneos debido a los nuevos paradigmas de la acción criminal en Brasil y en el mundo. Se llega a la conclusión de que el problema se refiere a una cuestión socioeconómica global, y que el tratamiento de esta lucha será exitoso si aún se insiste en tratar los efectos en lugar de las causas.

Palabras clave: La seguridad; Soberanía; Crimen; Tráfico de drogas; Guerras irregulares. 


\section{Introdução}

A abordagem ontológica da segurança pública condiciona a uma perspectiva passível de uma série de debates que ampliam sua fronteira de atuação. A segurança pública é a materialização do papel do Estado no uso de suas atribuições no qual é o único com legitimidade para o uso da força. Com o objetivo maior de garantir o direito fundamental à liberdade e, principalmente, à proteção dos direitos relacionados a segurança física e moral do indivíduo, a função do Estado neste quesito está relacionada a um campo estratégico no qual o mesmo se organiza: além da repressão em si, há também o uso de instrumentos preventivos e investigativos objetivando o combate a diversas formas criminais em paralelo às construções jurídicas pré-estabelecidas (Succi Jr., 2018).

Saint-Pierre (2011) destaca um ponto extremamente importante da noção dos atributos do Estado em função da segurança: o da dualidade na abordagem entre o interno e o externo; o interno estaria a cargo da instituição de polícia, que tem a função de controle e neutralização de possíveis conflitos dentro das fronteiras de determinado ente estatal; o externo tem função de garantir a defesa das fronteiras e a perpetuação existencial daquele Estado no Sistema Internacional, papel este operacionalmente atribuído às Forças Armadas.

\section{Metodologia}

Este artigo tem caráter exploratório, através de uma metodologia empírica-analítica, o qual utiliza-se métodos qualitativos com o fim de demonstrar os novos desafios contemporâneos por conta dos novos paradigmas de ação criminal no Brasil e no mundo. $\mathrm{O}$ objetivo geral é avaliar a perspectiva do crime transnacional como um desafio para a segurança pública em um contexto de novas táticas de combate utilizadas pelas organizações criminosas e quais seriam os caminhos para o Estado desenvolver uma ação eficiente para mitigar e, até mesmo, eliminar tais delitos.

\section{Polícia ou Forças Armadas?}

A ideia clássica de estabelecimento de um ambiente seguro remete basicamente à ausência de ameaças, ou seja, a paz entre Estados nacionais. Esta ideia de paz acaba se configurando como uma perspectiva extremamente ortodoxa do conceito dual Guerra x Paz, ou seja, uma perspectiva limitada a uma visão estritamente interestatal na qual a guerra seria 
apenas uma construção em que Estados Nacionais estariam envolvidos, e a paz o período em que não houvesse guerra entre estes.

Baseado na visão de soberania Westphaliana ${ }^{1}$ - o Estado é soberano dentro de suas fronteiras, na qual a construção da noção de soberania estatal é responsável pelo surgimento do Estado moderno. Esta representação do conceito de soberania requer algumas características para ser, de fato, efetiva: deve ser inalienável, absoluta e perpétua - o que definiria assim uma separação clara da concepção de segurança nacional e segurança interna, na qual a primeira está aliada à perspectiva estatocêntrica, ou seja, o Estado como ator central, e militarista. (ALSINA JR, 2019). Todavia, esse caráter acabou excedendo os limites teóricos e as concepções estabelecidas através da construção do sistema internacional de Estados, fugindo a esta noção da essência do conceito de segurança internacional e do âmbito de atuação das Forças Armadas, no qual os militares têm o papel de garantir a segurança nacional,

Este papel foi ampliado de uma forma singular na América Latina, mais especificamente. As Forças Armadas passaram a atuar de forma mais geral e a controlar também a política interna do Estado e suas respectivas instituições, como no exemplo das interferências para a derrubada de regimes civis políticos por questões ideológicas nas décadas de 1960 e 1970. Além disto, as forças armadas usavam seus recursos de Inteligência para investigar e reprimir possíveis levantes ou focos de resistência, e que possam gerar instabilidade e caos político. Um exemplo emblemático é a Operação Condor, neste mesmo período, um centro de inteligência e informações que contava com a contribuição entre regimes militares na América do Sul, com a função de investigar e reprimir células criminosas que, muitas vezes, se caracterizavam apenas por divergir ideologicamente ao regime estabelecido pelas forças militares.

O desafio de combate ao crime organizado foi ampliado drasticamente na consecução final da Guerra Fria, ao longo da década de 1980, em que uma das potências do regime bipolar, os Estados Unidos, se estabeleceu como a potência vitoriosa, sendo o grande Estado hegemônico no mundo. É neste período que as ameaças transfronteiriças ganham proporção e amplitudes maiores, como o exemplo do narcotráfico que aterrorizou o Governo Reagan nos Estados Unidos e gerou um grande debate na sociedade, principalmente sobre as formas de combate. Tais ameaças mesmo não sendo um processo novo, ganham uma maior notoriedade

\footnotetext{
${ }^{1}$ Após a Guerra dos Trinta Anos (1618 - 1648), o se criou o sistema Westphaliano, ou seja, "sistema internacional criado e reconhecido com o advento do Tratado de Paz de Westphalia em 1648 que tem no Estado nacional com sua summa potestas a base fundamental de engrenagens endógenas e exógenas internacionais. Sistema de uniformização estatal e de prevalência de seus institutos soberanos" (Castro, 2012, p.76).
} 
no cenário contemporâneo pela facilidade de seu fluxo transnacional e pela velocidade em que as operações são conduzidas e gerenciadas, resultado do advento de avanços tecnológicos nas áreas de comunicação e logística, possibilitando a disseminação de células criminais amplas e qualificadas para resistir à repressão estatal.

Conforme destaca Succi Jr (2018, p. 926), há inúmeros processos criminosos que podem ser enquadrados como noções não-convencionais da abordagem clássica da guerra, como o já citado "narcotráfico, o crime organizado internacional, tráfico de armas, terrorismo, degradação do meio ambiente, fundamentalismos religiosos, migrações, pobreza extrema". Tanto que, a partir daí, surgem termos como "Guerra ao Terror", "Guerra ao Narcotráfico”, por exemplo, os quais tentam aliar a perspectiva bélica ao combate de tais ações contrárias ao interesse do Estado. A qualificação do crime organizado gera um fator de impasse entre a opção pelo o uso dos recursos institucionais clássicos para o combate destas atividades criminosas ou a utilização das Forças Armadas para realizar tais operações de contenção, por ser um processo transnacional,

O argumento em prol da utilização das Forças Armadas insta no quesito da grande qualificação do inimigo, ou seja, a especialização operacional de tais atividades criminais na qual haveria uma incapacidade do instituto tradicional de polícia para lidar com tais problemas. Além disto, há um senso comum que remete à concepção de que há uma ineficiência na polícia por conta de um baixo grau de profissionalização, da suscetibilidade à corrupção e da falta de punição dos criminosos (Succi Jr., 2018). Em oposição, há um grande receio em apoiar o uso de operações militares em tais confrontos devido a uma possível falta de habilidade das Forças Armadas em estabelecer limites para tais operações, impactando em excessos no uso da Força e, principalmente, ao desrespeito aos direitos humanos (Succi Jr, 2018).

Assim, o conceito de Segurança Nacional passou a considerar tanto aspectos da defesa interna como da segurança pública em si, abordagens estas que não deveriam se misturar, uma vez que a segurança interna deveria ser associada estritamente ao caráter do papel das Forças Armadas na garantia da soberania na perspectiva Westphaliana supracitada, enquanto a ideia de segurança pública a garantia do respeito às leis, salvaguarda da ordem pública e das garantias individuais (Alsina Jr., 2019).

\section{Discussão e Resultados}

Diante da abordagem desenvolvida até então, é nítida a problemática relacionada ao desenvolvimento de células transnacionais que disseminam processos ilícitos pelas sociedades 
mundiais. O caso brasileiro se destaca também em uma perspectiva que vai além da questão das ações de grupos criminosos, voltada para problemas socioeconômicos. A adesão à criminalidade é um caminho para muitos que não possuem oportunidades de rendas mínimas para a subsistência, fator este em crescimento progressivo pelo fato de não haver soluções adequadas para tratar tal situação de forma estrutural e não apenas paliativa.

Saindo da discussão estrutural e direcionando à abordagem específica, um dos maiores problemas enfrentados pelo Estado brasileiro neste contexto é o narcotráfico. O tráfico de drogas e entorpecentes ilícitos movimenta grandes montantes de dinheiro e alimenta uma rede de criminalidade que vai muito além da comercialização de narcóticos - comércio ilegal de armas, estabelecimento de serviços à comunidade através da pirataria (tv por assinatura), comércio ilegal de bens de consumo (gás) e dinamização de jogos de azar proibidos pela legislação vigente. Conforme Chaves (2020, p.7), o uso de planos estratégicos vem sendo recurso utilizado pelo Estado para tentar reprimir crimes e garantir a segurança da população:

Apesar da redução da desigualdade, no Brasil, entre o fim do século XX e início do século XXI, o país foi circunstanciado por um vertiginoso aumento da violência. $\mathrm{O}$ fato correspondeu a reação governamental com a implementação de planos nacionais para a segurança pública como atributo de política de Estado construída de maneira técnica para atuação perene, articulada e consistente, pautada no contíguo de ações esboçadas como forma de afiançar a segurança individual e coletiva pelas instituições públicas.

Todavia, não há uma efetividade prática que tragam resultados satisfatórios. Segundo dados da Agência Deutschwelle (Hernandez, 2020), o Brasil é o segundo maior consumidor de cocaína no mundo, em número de usuários, ficando atrás apenas dos Estados Unidos. Isso demonstra o poder e a capilaridade das organizações criminosas no país, que se aproveitam da questão socioeconômica, em que há uma necessidade extrema de geração de renda das classes mais necessitadas, atraindo-a para o comércio ilegal deste narcótico.

Outro fator é a extensa fronteira territorial do país, no qual compartilha cerca de onze mil quilômetros com dez países, sendo que boa parte destes tem uma atividade de comércio ilegal de drogas muito extensa, como no caso da Colômbia; há também a facilidade encontrada por grupos especiais do crime conforme afirma Hernandez (2020), como o caso do Primeiro Comando da Capital (PCC), grupo criado em 1993 na cidade de São Paulo e que possui uma capilaridade de operações ao longo de praticamente todo o país. Tal facilidade se estabelece pela dificuldade investigativa e a falta de combate mais sólido ao tráfico de drogas, fatores estes explicitados anteriormente sobre a eficiência dos processos novos de guerras irregulares no qual 
as operações criminosas ganham velocidade e eficiência, além da incapacidade de combate mais efetivo do corpo policial pela falta de um alvo bem definido.

Rotas transnacionais são estabelecidas por tais grupos e o PCC é um dos beneficiados por este network entre fronteiras, como o caso da "rota caipira" com início no Peru, passando pela Bolívia, Paraguai e terminando no Brasil - segundo Cueto (2020), Peru e Bolívia se estabelecem como produtores consolidados da folha de coca enquanto os paraguaios são fortes na produção da maconha; tal rota finda no Brasil justamente por ser um mercado que demanda bastante narcóticos e, principalmente pelos altos níveis de preços. Um outro ponto ainda segundo matéria da BBC Mundo (Cueto, 2020) é o fator da extensão territorial brasileira, florestas e vegetações diversas, o que impede uma atuação de combate mais eficiente e, principalmente pela sua grande extensão litorânea e a canalização dos afluentes do Rio Amazonas. Além de atingir a demanda do mercado brasileiro, há inda a saída via marítima, principalmente, para o mercado europeu, no qual o Brasil é um dos principais remetentes na América Latina da droga ilícita para o exterior.

O caráter lucrativo estabelece grandes corporações que operam em adjacência aos principais núcleos do crime organizado, neste caso o PCC, com uma organização operacional eficaz e capaz de burlar os sistemas de repressão policiais e legais. A tentativa de promover agentes infiltrados nessa organização não gerou resultados efetivos e o risco da operação é extremamente alto.

\section{Considerações Finais}

O debate sobre as novas formas de crime transnacional está em pauta nas principais sociedades mundiais as quais se deparam com problemas complexos e que desestabilizam a condução normal no andamento de determinado Estado. Decerto, ações de combate estão sendo pensadas e trabalhadas pelas principais unidades de elite nas polícias no mundo, porém ainda não há respostas claras quanto ao direcionamento de soluções eficientes.

A falta de efetividade nas ações gera um questionamento quanto ao papel da polícia neste combate uma vez que, também devido a problemas socioeconômicos como baixos salários de policiais, impunidade em processos de corrupção, falta de preparo técnico e psicológico do contingente operacional, transforma a questão em um problema orgânico, ou seja, que se auto alimenta e se fortalece perante o combate estatal. Dentro desta perspectiva, urge uma solução mais efetiva que, de certa forma, parece envolver impreterivelmente a solução de problemas socioeconômicos no mundo, o que requer uma condução em conjunto das 
principais lideranças no mundo. Resta saber, de fato, até que ponto o interesse em unir forças dos países mais capazes para gerar tal força tarefa em prol de um desenvolvimento sustentável; tal interesse requer uma mudança drástica de paradigmas e, principalmente, uma revisão de prioridades na agenda global em busca do desenvolvimento mais amplo.

\section{Referências}

Alsina Jr, J. P. (2018). Ensaios de Grande Estratégia Brasileira. Rio de Janeiro: Fundação Getúlio Vargas.

Castro, T. (2012). Teoria das Relações Internacionais. Brasília: FUNAG.

Chaves, A. B. P. (2020). Estado e o Monopólio da Violência: os planos de segurança pública no Brasil. Research, Society and Development, 9(7), e125973887. https://doi.org/10.33448/rsdv9i7.3887

Cueto, J. C. (2020). Como o crime organizado brasileiro se apoderou das principais rotas do tráfico na América do Sul. 07.03.2020. Recuperado de <https://www.dw.com/pt-br/brasilcampe $\%$ C3\%A3o-em-consumo-de-coca\%C3\%ADna-e-em-viol\%C3\%AAncia/a-50172622>

Finnemore, M. (2004). The purpose of intervention: changing beliefs about the use of force. New York: Cornell University Press.

Gianturco, A.(2017). A Ciência da Política: uma introdução. Rio de Janeiro: Forense.

Hernandez, A. (2019), campeão em consumo de cocaína e em violência. Agência DW. 26.08.2019. Recuperado de <https://www.dw.com/pt-br/brasil-campe\%C3\%A3o-emconsumo-de-coca\%C3\%ADna-e-em-viol\%C3\%AAncia/a-50172622>

Jackson, R., Sorensen, G. (2013). Introdução as Relações Internacionais. Rio de Janeiro: Zahar.

Lessa, A. C. (2005). História das Relações Internacionais: A Pax Britannica e o mundo do século XIX. Petrópolis: Editora Vozes. 
Magalhães, J. N. (2016). Formação do Conceito de Soberania: história de um paradoxo. São Paulo: Saraiva.

Moreira, A. (1999). Teoria das Relações Internacionais. Coimbra: Almedina.

Saint-Pierre, H. L. (2011). "Defesa"ou "segurança"? Reflexões em torno de conceitos e ideologias. Contexto Internacional. 33(2), 407-33.

Succi Jr. (2018). D.P. Segurança Pública Interna. Dicionário de Segurança e Defesa.Org. Héctor Luis Saint-Pierre e Marina Gisela Vitelli. São Paulo: Editora Unesp, 2018. 923-30.

Visacro, A. (2019). Guerra Irregular: terrorismo, guerrilha e movimentos de resistência ao longo da história. São Paulo: Contexto.

Weber, C. Simulating Sovereignty (1995). Intervention, the State, and symbolic exchange. Cambridge: Cambridge University Press.

\section{Porcentagem de contribuição de cada autor no manuscrito}

Rivaldo Ribeiro Sobral Neto - $50 \%$

Murilo Jacques Barbosa - $50 \%$ 